\title{
Ability for self-care in urban living older people in southern Norway
}

This article was published in the following Dove Press journal:

Journal of Multidisciplinary Healthcare

23 March 2012

Number of times this article has been viewed

\author{
Kari Sundsli, ${ }^{1,2}$ \\ Ulrika Söderhamn ${ }^{2}$ \\ Geir Arild Espnes ${ }^{1,3}$ \\ Olle Söderhamn² \\ 'Department of Social Work and \\ Health Science, Faculty of Social \\ Sciences and Technology Management, \\ NTNU, Trondheim, Norway; ${ }^{2}$ Centre \\ for Caring Research - Southern \\ Norway, Faculty of Health and \\ Sport Sciences, University of Agder, \\ Grimstad, Norway; ${ }^{3}$ Research Centre \\ for Health Promotion and Resources \\ HiST-NTNU, Department of Social \\ Work and Health Science, Faculty \\ of Social Sciences and Technology \\ Management, NTNU, Trondheim, \\ Norway
}

Correspondence: Kari Sundsli

Centre for Caring Research - Southern

Norway, Faculty of Health and Sport

Sciences, PO Box 509, NO-4898

Grimstad, Norway

Tel +4737233784

Email kari.sundsli@uia.no
Background: The number of older people living in urban environments throughout the world will increase in the coming years. There is a trend in most European countries towards improved health among older people, and increased life expectancy for both women and men. Norway has experienced less increase in life expectancy than some other European countries, and it is therefore important to investigate older urban Norwegian people's health and ways of living in a self-care environment, with special regard to health promotion.

Aim: The aim of this study was to describe self-care ability among home-dwelling older (65+ years) individuals living in urban areas in southern Norway in relation to general living conditions, sense of coherence (SOC), screened nutritional state, physical activity, perceived self-reported health, mental health, and perceived life situation.

Methods: In 2010, a randomized sample of 1044 men and women aged 65+ years who were living in urban areas in southern Norway answered a postal questionnaire consisting of five instruments, some background variables, and 17 health-related questions. Univariate and multivariate statistical methods were used in the analyses of the data.

Results: The mean age of the participants was 74.8 years $(\mathrm{SD}=7.1)$. Eighty-three percent of the participants had higher abilities to care for themselves. Self-care agency, perceived good health, being active, being frequently active, good mental health, not being at risk of undernutrition, and satisfaction with life were all positively related to self-care ability. Negative factors were perceived helplessness, receiving home nursing, being anxious, and being at a more advanced age. People aged $85+$ years had worse mental health, were less physically active, and more at risk of undernutrition.

Conclusion: Health professionals should focus on the health-promoting factors that reinforce older people's ability to care for themselves, and be aware of important symptoms and signs associated with a reduction in a person's self-care ability. Politicians should assume responsibility for health care with a special regard to senior citizens.

Keywords: activity, aged, health promotion, mental health, perceived health, undernutrition

\section{Introduction}

Population aging and urbanization are the culmination of successful human development, but will be major challenges in the coming century. Today, half of the world's population lives in urban areas, which is defined as living close to a city community, or in a city. ${ }^{1,2}$ Nearly two-thirds of the world's population will live in urban areas within the next 30 years. ${ }^{1,3}$ Cities with less than five million inhabitants will contain most of the world's population in the 21 st century, and it will be of great importance to view urban health as an international and global issue. ${ }^{1}$ 
As is seen in most west European countries, Norway's demographic and epidemiological development are undergoing significant changes. One of these changes is the increasing number of older people in the population, ${ }^{4}$ with the number of people aged 67 years or more expected to double by 2050 . In the four largest cities in Norway, $11 \%$ of the population is currently older than 67 years. ${ }^{5}$ The majority of the Norwegian population is in good health. Most sections of the population have seen increased life expectancy during the last 25 years due to improved living conditions. Since 1950, life expectancy has increased by ten years for both women and men in Norway - while this is good, other European countries have seen a greater improvement. ${ }^{4}$

Health has become a fundamental and essential goal for individuals. Higgs et $\mathrm{l}^{6}{ }^{6}$ state that the emergence of the will to health is considered as a dominant discourse in later life. Furthermore, they emphasize that health not only enables a state of personal wellbeing, but is also as central to leading an agentic, fulfilling life. ${ }^{6}$ This view of health indicates that older people can be categorized either as active "third agers" who contribute to their own positive health status, or as dependent "fourth agers" who are passive consumers of health care. According to the same authors, the research on later life needs to focus on something more than understanding older people as being old and sick. Instead, the new realities of aging in a consumer society have the potential to guide research towards investigating older people's potential to engage in agency at both the level of society in general and at the level of personal health concerns. ${ }^{6}$

Older people's mental health is influenced by life experiences, which can be both good and bad. The good side of this seems to be that emotional reactions (both positive and negative) become less strong, that older people more easily adjust to new physical environments, and are more clever in adjusting goals and expectations than younger people tend to be. ${ }^{7}$ The loss of or changes in former roles, such as those of being a husband or wife, of being gainfully employed or in other former social roles, all affect older people's mental health, and can also have an impact on physical health. ${ }^{7}$

Although the majority of older people in Norway have good mental health, many of those aged 75 years and above are depressed and lonely. ${ }^{7}$ In a study by Kvaal et al, ${ }^{8}$ an overall prevalence of anxiety and depressive disorders was seen in $3.1 \%$ and $9.7 \%$, respectively, of older people in Great Britain. A recent Swedish study of life satisfaction among senior citizens found that only $15 \%$ of women had no depressive symptoms, and depressive and tensive symptoms were more severe as age increased, and these symptoms were also more prevalent in women than in men. ${ }^{9}$ About $25 \%$ of the men claimed to be totally free of these symptoms.

Health promotion is the process of enabling people to increase control over and improve their health, and thereby enabling them to lead an active, productive life towards wellbeing and quality of life. ${ }^{10}$ Aron Antonovsky, the creator of the sense of coherence (SOC) concept, introduced the concept of salutogenesis and claimed that people's life orientation will have an impact on health. ${ }^{10}$

SOC was introduced in the late 1970 s, and is a way of seeing the world that facilitates successful coping with stressors in all cultures. It develops in the course of one's life and reaches a stable state in adults. The SOC concept is a global orientation and is constituted by the three components of comprehensibility, manageability, and meaningfulness. It is a major determinant for maintaining the individual's position on the health ease-disease continuum and possible movement(s) towards a healthy end. SOC expresses the degree to which the person has a pervasive, enduring dynamic feeling of confidence that stimuli from which the internal and external environments are structured, predictable, and explicable. ${ }^{11}$ Since SOC is about resources for health and problem solving, it is conceptually and empirically related to self-care. ${ }^{12}$

Self-care is a multidimensional health-related concept that can have different interpretations. Self-care is the practice of activities that individuals initiate and do on their own behalf in maintaining health and well-being. ${ }^{13}$ As a health resource, self-care is able to promote self-responsibility as a part of health care, and is an ability to care for oneself regardless of health condition. It is linked less to learning facts about specific health issues and more to learning how to set goals and organize resources and action strategies. ${ }^{14,15}$

Nutrition is an essential topic in the discussion of selfcare, with special regard given to health promotion, health maintenance, disease prevention, and disease treatment. ${ }^{16}$ This is easily seen among older people where the complex phenomenon of aging includes physiological and psychological changes linked to social conditions. The physiological changes of aging may affect nutritional needs, and older people may be at an increased risk of nutritional deficiencies because they cannot meet certain nutritional needs. ${ }^{17}$ Söderhamn et al have reported that $69 \%$ of older patients are nutritionally at-risk, and that being at medium or high risk was associated with perceived ill health, lower self-care ability, and a weaker SOC. ${ }^{12}$

Being active has been shown to be a significant positive factor for self-care ability in older home dwelling people. ${ }^{15}$ 
Positive effects of physical activity on health and wellbeing among older people have been reported in a number of studies, ${ }^{18-20}$ and all older people should be encouraged to remain as active as possible, and - if they are sedentary increase their regular activity levels in modest ways with the support of others. ${ }^{21}$ It is well known that being in good health positively influences people's life situation and their perceptions of life. This is also the case for older people. ${ }^{22-24}$

It is well documented that older urban people report higher self-esteem, increased positive moods, better emotional health, and more satisfaction with aging than those in rural areas. ${ }^{25}$ Older people living in urban areas also report having higher functional health status scores and a higher degree of physical function and mental health than rural people. $^{26}$

There is, however, a lack of knowledge about factors that influence self-care ability among older home-dwelling people in urban areas in Norway. A better understanding of this would be useful for health professionals, politicians, and other stakeholders in order to identify individuals at risk for lower self-care ability, and to determine how to plan care for this group, both on an individual and societal level.

\section{Aim}

The aim of this study was to describe self-care ability among home-dwelling older (aged 65+ years) individuals living in urban areas in southern Norway in relation to general living conditions, sense of coherence (SOC), screened nutritional state, physical activity, perceived self-reported health, mental health, and perceived life situation.

\section{Methods}

\section{Design and participants}

A descriptive cross-sectional design with a quantitative approach was used in the current study. In the spring of 2010, a questionnaire was sent to a randomized sample of 3016 people aged $65+$ years who were living in urban areas in five counties in southern Norway. The urban areas had 5939 to 51,359 inhabitants. ${ }^{5}$ A total of 831 people initially completed the questionnaire, and following one reminder another 213 people responded. Therefore, a total number of 1044 participants (34.6\% of those asked to participate) were included in the study.

\section{Data collection}

The self-report questionnaire used in this study consisted of five instruments, background variables concerning age, sex, marital status, living arrangement, and occupation, and 17 health-related questions that could be answered either 'yes' or 'no'. The survey included questions about perceived health, whether the person was receiving regular help to manage daily life, and further questions concerning frequency of food preparation, physical activity, and contact with family, neighbors, and friends.

\section{The instruments}

The self-care ability scale for the elderly (SASE) ${ }^{27}$ is a 17 item, five-point Likert scale based on Pörn's ${ }^{28}$ theory of health and adaptedness, and is designed to measure perceived self-care ability, ie, the ability to maintain health and wellbeing. The items reflect areas that may be of concern for older people, such as activities of daily living, mastery, wellbeing, volition, determination, loneliness, and dressing. ${ }^{27}$ Each item receives a score that ranges from 1 ("totally disagree") to 5 ("totally agree"), and the total score ranges between 17 and 85 with a higher score indicating greater perceived self-care ability. A cut-off score of $\geq 69$ has been found to identify those with higher self-care ability and $<69$ for those with lower self-care ability. Four items, negatively stated, are reversed in the summary of the scores. SASE has been tested for reliability and validity. ${ }^{27,29,30}$ Cronbach's alpha values of between 0.68 and 0.89 have been reported..$^{15,27,30}$

The appraisal of self-care agency scale (ASA-A) is an instrument for self-reporting the activation of power and engagement in self-care activities, ${ }^{31,32}$ which is based on Orem's self-care deficit theory of nursing. ${ }^{13}$ It is a Likerttype scale including 24 items. Each item has five response categories ranging from 1 ("totally disagree") to 5 ("totally agree"). The total score ranges from 24 to 120, with a higher score indicating greater self-care agency. Nine items are negatively stated, and have to be reversed in the summation of the scores. Reliability and validity of ASA-A have been tested in several studies in different countries. ${ }^{30-33}$ Cronbach's alpha values of between 0.72 and 0.86 have been reported among home-dwelling older people ${ }^{15}$ and 0.77 among older people with health problems. ${ }^{31}$

In the current study, the 29-item SOC ${ }^{11}$ scale has been used. The SOC scale is a semantic differential scale on the ordinal level with two anchoring phrases, and with scores ranging from 1 to 7 . Total scores range from 29 to 203, with a higher score expressing a stronger SOC. Eleven items address comprehensibility, ten items address manageability, and eight items address meaningfulness. Thirteen items are negatively stated and must be reversed in the summation of the scores. The scale is found to be a reliable and valid instrument and has been used in several studies, and in different 
languages. ${ }^{11,34-36}$ In studies from a number of different countries, Cronbach's alpha values between 0.82 and 0.95 have been reported. ${ }^{36}$

The nutritional form for the elderly (NUFFE) $)^{37,38}$ is a nutritional-screening instrument with 15 three-point items concerning weight loss, changes in dietary intake, appetite, food and fluid intake, eating difficulties, possibility of obtaining food products, company at meals, activity, and number of medications. Each item is given a score that ranges between 0 and 2 , in which the most advantageous score is 0 and the most disadvantageous is 2 . The maximum score for the NUFFE is 30 , with higher screening scores indicating higher risk for undernutrition. In the Norwegian version of NUFFE a score of 6 indicates a medium risk of undernutrition, and a score of 11 indicates a high risk of undernutrition. The instrument has sufficient psychometric properties to perform a nutritional screening of older people. A Cronbach's alpha value between 0.70 and 0.77 has been found among older individuals. ${ }^{37-39}$

The Goldberg's general health questionnaire (GHQ-30 $)^{40}$ is a four-point Likert-type scale, with 30 items that aim to assess mental state. Fifteen items are positively worded and 15 are negatively worded. The scale is summative where the minimum score is 0 and the maximum is 90 , with higher scores indicating more severe conditions. The questionnaire is a widely accepted and reliable scale for establishing minor psychiatric disorders (such as depression, anxiety, insomnia, lack of energy, social dysfunction, unhappiness, inadequate coping, and feelings of incompetence) among general populations, and GHQ-30 is one of the most used instruments for the assessment of older people. ${ }^{40,41}$ The Norwegian version has been tested and found to be a reliable and valid instrument for assessing the mental state of older home-living people, and has a Cronbach's alpha value of $0.92 .{ }^{42}$

\section{Data analyses}

All data were analyzed with PASW Statistics 18 (SPSS Inc, Chicago, IL). Descriptive statistics were used to describe the study group. Interval and ordinal data are presented with means $(\mathrm{M})$ and standard deviations (SD). Nominal data are presented with numbers $(n)$ and percentages (\%).

Chi-square tests, Mann-Whitney $U$-tests for independent samples (two-tailed significance), and $t$-tests for independent samples (two-tailed significance) were used for testing differences between groups regarding nominal, ordinal, and interval data, respectively. Statistical significance was defined as a $P$-value $<0.05$.

Some data were missing in some questionnaires. These missing data appeared to be completely random. When up to five values were missing in the ASA-A, SASE, or SOC instruments, the neutral score was put in the place of the missing values. When there were more than five missing values in one scale for a specific individual, that particular scale was not included in the analyses for that individual.

Linear stepwise regression analyses were performed in order to find factors to explain self-care ability, both in the total study group and in three age cohorts of 65-74 years, 75-84 year, and $85+$ years of age. It was hypothesized that self-care ability could be explained by a number of healthrelated factors that have been found in other studies. ${ }^{15,43}$ Another hypothesis was that the health-related factors that explain self-care ability would differ between the three age cohorts. In the regression analyses, the dependent variable was SASE scores, while the independent variables on the nominal level were sex, living alone, types of dwelling, occupation, perceived health, perceived helplessness, feeling lonely, being anxious, being satisfied with life, suffering from a chronic disease or handicap, being active, perceived social contact when being physically active, perceived well-being when being physically active, sufficient eating, preparing food, receiving food distribution, receiving home nursing, receiving home care, receiving family help, having contact with people in their environment, and living in smaller/ larger cities. The variables on the nominal level were coded to differentiate their binary status. Variables included on the ordinal level were frequency of contact with family, frequency of contact with neighbors, frequency of contact with friends, frequency of physical activity, NUFFE scores, ASA-A scores, GHQ-30 scores, and SOC scores. Age was the only variable on the interval level.

The choice of independent variables was based on variables that in univariate analyses reached a $P$-value $<0.2$ when compared to SASE scores. The number of these variables was suitable regarding the sample size. ${ }^{44}$ When the variables were correlated to each other, a large number had a correlation coefficient of 0.20 to 0.40 . The highest correlation $(r=0.64)$ occurred between SOC and GHQ.

The emerged factors in the linear stepwise regression analyses and SASE mean scores were investigated in relation to age. A one-way ANOVA with a Bonferroni post-hoc test was used to test differences regarding interval and ordinal data between the three age cohorts. A chi-square test was used to test differences between these age cohorts regarding nominal data, and a chi-square test was also used to identify the groups between which the differences were to be found. Multiple comparisons were adjusted with the Bonferroni method. ${ }^{44}$ 


\section{Ethical considerations}

The study was designed and implemented according to the Declaration of Helsinki ${ }^{45}$ and common principles used in clinical research. ${ }^{45,46}$ The Regional Committee for Medical Research Ethics in southern Norway approved the study (REK Sør-Øst A: 2009/1321). The participants were informed about the study by a written paper that was included with the questionnaire, and participants were guaranteed anonymity and confidentiality. The returning of a completed questionnaire was considered to be informed consent to participate in the study. The questionnaires and the participant identification numbers were kept locked in different fireproof cabinets to ensure confidentiality and security.

\section{Results}

\section{Participants and nonparticipants}

The mean age of the participants ( $n=1044$ ) was 74.8 years $(\mathrm{SD}=7.1)$. The study group consisted of 529 females $(50.7 \%)$ and 515 males $(49.3 \%)$. The mean age of the females was 75.1 years $(\mathrm{SD}=7.4$ ) while the mean age of the males was 74.5 years $(\mathrm{SD}=6.8)$. Among the participants, 340 individuals $(32.6 \%)$ reported that they were living alone and $693(63.4 \%)$ that they were married or cohabitant. Furthermore, 1008 individuals (96.6\%) lived in their own homes and $25(2.4 \%)$ in sheltered accommodations, 492 individuals (47.1\%) had a professional or white collar occupational background, and 516 (49.4\%) had an occupational background as blue collar workers or home workers.

The nonparticipants $(n=1972)$ had a mean age of 77.2 years $(\mathrm{SD}=7.8)$, which was significantly higher than that of the participants $(P<0.001)$. The proportion of females (69.5\%) among the nonparticipants was higher than among the participants $(P<0.001)$.

\section{Self-care ability}

Mean SASE score in the study group $(n=1008)$ was 74.6 $(\mathrm{SD}=9.9)$. Eight hundred forty participants $(83.3 \%)$ were found to have higher self-care ability (score $\geq 69$ ), with these people having a mean SASE score of 78.2 $(\mathrm{SD}=4.3)$, and a range of scores from 69 to 85 . One hundred sixtyeight people (16.7\%) had lower self-care ability (score $<$ 69), with a mean SASE score of 56.9 (SD = 11.0), ranging from 17 to 68 . The difference between the groups with lower and higher self-care ability was found to be significant $(P<0.001)$. Participants living in smaller cities ( $\leq 20,000$ inhabitants) had lower self-care ability $(\mathrm{M}=74.1$, $\mathrm{SD}=9.4)$ compared to those $(\mathrm{M}=74.8, \mathrm{SD}=10.1)$ living in larger cities $(>20,000$ inhabitants $)(P=0.037)$.

\section{Associated factors for self-care ability}

Table 1 shows how eleven factors explained self-care ability. SASE scores were positively related to self-care agency, perceived good health, being active, being frequently physically active, good mental health, lower risk of undernutrition, and being satisfied with life. Perceived helplessness, receiving home nursing, being anxious, and advanced age were negatively related to SASE scores.

In the linear stepwise regression analysis, self-care agency (ASA-A) made the strongest contribution to the explanation of self-care ability as measured by SASE. Mean ASA-score in the study group was $92.4(\mathrm{SD}=10.7)$. Mental health assessed with GHQ also contributed strongly to selfcare ability, and most of the people were in good mental health $(\mathrm{M}=24.1, \mathrm{SD}=8.8)$. The majority $(n=1044)$ of the respondents reported that they had good health $(87.2 \%)$ and a total of 636 individuals (61.0\%) were physically active every day. In addition, 932 people (89.3\%) perceived well-being when they were physically active. Participants who were physically active every day had higher self-care ability than those who were physically active once a week $(P<0.001)$. There was also a difference regarding self-care ability between individuals who were physically active every day and those who were active less than once a week, or never active $(P<0.001)$. Furthermore, most of the individuals had a low risk of undernutrition, with a mean NUFFE score of $4.0(\mathrm{SD}=3.1)$. Eighty-seven percent perceived themselves as being active, and most of the participants $(90.2 \%)$ felt satisfied with their lives.

Fifty-four individuals (5.5\%) received formal home nursing care, and this was strongly negatively correlated to self-care ability. A total of 107 people (10.6\%) perceived helplessness, which was a negative factor concerning

Table I Associated factors for SASE scores

\begin{tabular}{lll}
\hline Variables & $\mathbf{R}^{2}=\mathbf{0 . 6 0}$ & \\
\cline { 2 - 3 } & $\mathbf{B e t a}$ & $\mathbf{P}$-value \\
\hline GHQ scores & -0.137 & $<0.001$ \\
Receiving home nursing & -0.217 & $<0.00 \mathrm{I}$ \\
ASA-A scores & 0.236 & $<0.00 \mathrm{I}$ \\
Perceived helplessness & -0.164 & $<0.00 \mathrm{I}$ \\
Age & -0.126 & $<0.00 \mathrm{I}$ \\
Perceived health & 0.090 & 0.002 \\
Being anxious & -0.091 & 0.002 \\
Frequencies of physical activity & $0.08 \mathrm{I}$ & 0.004 \\
Being active & 0.068 & 0.020 \\
NUFFE scores & -0.072 & 0.023 \\
Being satisfied with life & 0.066 & 0.027 \\
\hline
\end{tabular}

Abbreviations: ASA-A, appraisal of self-care agency scale; GHQ, Goldberg's general health questionnaire; NUFFE, nutritional form for the elderly; SASE, self-care ability scale for the elderly; $\mathrm{R}^{2}$, determination coefficient; Beta, standardized regression coefficient. 
self-care ability. More advanced age also contributed negatively to self-care ability. One hundred thirteen individuals $(11.1 \%)$ perceived themselves as anxious.

Table 2 shows that there were differences in mean SASE scores between the three age cohorts, with the oldest cohort reporting lower self-care ability. Differences between the age cohorts were also found regarding the obtained factors influencing self-care ability.

\section{Factors influencing positively on self-care ability}

The respondents in the oldest cohort reported worse mental health than those in the other two cohorts. Self-care agency was significantly different between all three age cohorts. The majority of the participants in all age cohorts perceived themselves to be in good health, with the youngest cohort having the greatest proportion of individuals who perceived themselves to be in good health.

All cohorts included a number of respondents who were physically active once a week or more, with the highest frequency of this reported in the youngest cohort.
The majority of respondents in the cohorts considered themselves to be active, with the youngest cohort again having the highest proportion of people reporting this. The oldest cohort showed a mean NUFFE score that indicated risk of undernutrition, while the other two cohorts did not. The majority of respondents in all cohorts showed satisfaction with life, with no significant differences between the cohorts.

\section{Factors influencing negatively on self-care ability}

Twenty-three percent of the respondents in the oldest cohort received home nursing, which was the greatest proportion within the three age cohorts. Less than half of the respondents in each of the cohorts perceived helplessness, with the largest proportion in the oldest cohort. Advanced age was a risk factor for lower self-care ability, and this was strongly reflected in the oldest cohort. The oldest respondents often experienced anxiety compared to the two other age cohorts. No significant difference was found between the youngest and the intermediate cohort.

Table 2 SASE and its factors related to age cohorts

\begin{tabular}{|c|c|c|c|c|}
\hline & $\begin{array}{l}\text { Age cohort A } \\
65-74 \text { years } \\
n=574\end{array}$ & $\begin{array}{l}\text { Age cohort B } \\
75-84 \text { years } \\
n=337\end{array}$ & $\begin{array}{l}\text { Age cohort C } \\
85+\text { years } \\
n=133\end{array}$ & $P$-value \\
\hline \multirow[t]{2}{*}{ SASE [M (SD)] } & $77.2(7.2)$ & $73.4(9.7)$ & $66.1(14.5)$ & $<0.012^{c, e, g}$ \\
\hline & $n=561$ & $n=321$ & $n=126$ & \\
\hline \multirow[t]{2}{*}{ GHQ [M (SD)] } & $22.9(7.6)$ & $24.5(8.9)$ & $29.0(12.3)$ & $<0.012^{\mathrm{a}, \mathrm{e}, \mathrm{g}}$ \\
\hline & $n=538$ & $n=296$ & $n=104$ & \\
\hline \multirow[t]{2}{*}{ Receiving home nursing [no (\%)] } & $9(1.6)$ & $15(4.6)$ & $30(23.1)$ & $<0.012^{\mathrm{b}, \mathrm{e}, \mathrm{g}}$ \\
\hline & $n=562$ & $n=326$ & $n=130$ & \\
\hline \multirow[t]{2}{*}{ ASA-A [M (SD)] } & $94.9(10.2)$ & $90.6(9.8)$ & $86.0(11.1)$ & $<0.012^{\mathrm{ce}, \mathrm{g}}$ \\
\hline & $n=547$ & $n=314$ & $n=118$ & \\
\hline \multirow[t]{2}{*}{ Perceived helplessness [no (\%)] } & $36(6.4)$ & $42(13.1)$ & $29(22.7)$ & $<0.012^{\mathrm{b}, \mathrm{e}, \mathrm{f}}$ \\
\hline & $n=562$ & $n=320$ & $n=128$ & \\
\hline \multirow[t]{2}{*}{ Age [M (SD)] } & $69.4(2.8)$ & $79.0(2.9)$ & $88.0(2.4)$ & $<0.012^{\mathrm{c}, \mathrm{e}, \mathrm{g}}$ \\
\hline & $n=574$ & $n=337$ & $n=133$ & \\
\hline \multirow[t]{2}{*}{ Perceived health [no (\%)] } & $530(96.2)$ & $256(90.5)$ & $97(83.6)$ & $<0.012^{\text {be,ff }}$ \\
\hline & $n=551$ & $n=283$ & $n=116$ & \\
\hline \multirow[t]{2}{*}{ Being anxious [no (\%)] } & $49(8.7)$ & $40(12.3)$ & $24(18.9)$ & $0.036^{d}$ \\
\hline & $n=563$ & $n=326$ & $n=127$ & \\
\hline \multirow[t]{2}{*}{ Frequencies physical activity [M (SD)] } & $2.56(0.7)$ & $2.44(0.8)$ & $2.21(1.1)$ & $<0.012^{e, f}$ \\
\hline & $n=563$ & $n=325$ & $n=128$ & \\
\hline \multirow[t]{2}{*}{ Being active [no (\%)] } & $503(89.7)$ & $277(85.8)$ & $98(76.6)$ & $<0.012^{e, f}$ \\
\hline & $n=561$ & $n=323$ & $n=128$ & \\
\hline \multirow[t]{2}{*}{ NUFFE [M (SD)] } & $3.2(2.3)$ & $4.3(3.3)$ & $6.6(4.1)$ & $<0.012^{\mathrm{ce}, \mathrm{g} g}$ \\
\hline & $n=524$ & $n=306$ & $n=116$ & \\
\hline \multirow[t]{2}{*}{ Being satisfied with life [no (\%)] } & $515(92.1)$ & $288(89.7)$ & $105(82.7)$ & 0.06 \\
\hline & $n=559$ & $n=321$ & $n=127$ & \\
\hline
\end{tabular}

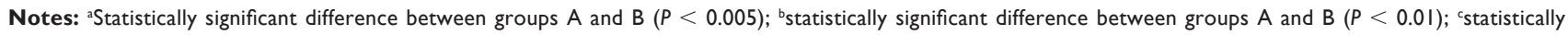

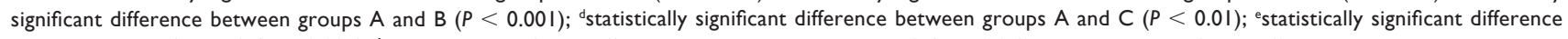
between groups $A$ and $C(P<0.001)$; 'statistically significant difference between groups $B$ and $C(P<0.05)$; sstatistically significant difference between groups $B$ and $C(P<0.001)$.

Abbreviations: ASA-A, appraisal of self-care agency scale; GHQ, Goldberg's general health questionnaire; NUFFE, nutritional form for the elderly; SASE, self-care ability scale for the elderly. 


\section{Factors influencing self-care ability in the three age cohorts}

The regression analyses for the three age cohorts showed results that differed from those seen in the total study group (Table 3). ASA-A was a positive influencing factor in all age cohorts. Perceived health and being active were both positive factors in the two youngest cohorts, while perceived helplessness and being anxious were found to be negative factors. Age had a negative influence for individuals aged 75-84 years, and GHQ-scores contributed negatively in the two oldest cohorts. Receiving home nursing, frequency of physical activity, and being satisfied with life were all influential in the oldest and the youngest cohorts.

\section{Discussion}

The aim of this study was to describe self-care ability among home-dwelling older (aged 65+ years) individuals living in urban areas in southern Norway in relation to general living conditions, sense of coherence (SOC), screened nutritional state, physical activity, perceived self-reported health, mental health, and perceived life situation.

A high mean SASE score $(\mathrm{M}=74.6)$ was found among the people in the study group, and SASE scores were

Table 3 Regression analyses for self-care ability (SASE scores) in three age cohorts

\begin{tabular}{|c|c|c|c|}
\hline & Independent variables & Beta & $P$-values \\
\hline \multicolumn{4}{|c|}{ 65-74 years } \\
\hline \multirow[t]{7}{*}{$n=574$} & Perceived helplessness & -0.261 & $<0.001$ \\
\hline & ASA-A scores & 0.290 & $<0.001$ \\
\hline & Receiving home nursing & -0.239 & $<0.001$ \\
\hline & Being anxious & -0.166 & $<0.001$ \\
\hline & Being active & 0.095 & 0.013 \\
\hline & Perceived health & 0.099 & 0.007 \\
\hline & Frequency of physical activity & 0.094 & 0.011 \\
\hline $\mathrm{R}^{2}=0.5 \mathrm{I}$ & Being satisfied with life & 0.077 & 0.036 \\
\hline \multicolumn{4}{|c|}{$75-84$ years } \\
\hline \multirow[t]{6}{*}{$n=337$} & Perceived helplessness & -0.142 & 0.032 \\
\hline & ASA-A scores & 0.298 & $<0.001$ \\
\hline & Perceived health & 0.194 & 0.001 \\
\hline & Being anxious & -0.147 & 0.014 \\
\hline & Age & -0.108 & 0.017 \\
\hline & GHQ scores & -0.130 & 0.021 \\
\hline$R^{2}=0.56$ & Being active & 0.116 & 0.021 \\
\hline \multicolumn{4}{|l|}{$85+$ years } \\
\hline \multirow[t]{4}{*}{$n=133$} & GHQ scores & -0.255 & 0.001 \\
\hline & Receiving home nursing & -0.312 & $<0.001$ \\
\hline & Frequency of physical activity & 0.277 & $<0.001$ \\
\hline & ASA-A scores & 0.200 & 0.004 \\
\hline$R^{2}=0.79$ & Being satisfied with life & 0.162 & 0.024 \\
\hline
\end{tabular}

Abbreviations: ASA-A, appraisal of self-care agency scale; GHQ, Goldberg's general health questionnaire; SASE, self-care ability scale for the elderly; $\mathrm{R}^{2}$, determination coefficient; Beta, standardized regression coefficient. positively related to the health promotion factors of selfcare agency, perceived good health, being active and being frequently physically active, good mental health, lower risk of undernutrition, and being satisfied with life. Perceived helplessness, receiving home nursing, being anxious, and advanced age were negatively related to SASE scores. Most of these results are in line with the results of a previous corresponding study. ${ }^{15}$ Having a high SASE score indicates that people are in control of their own care and are responsible for making choices of their own. This indicates that people aged 65 years and above are able to learn how to set goals and organize resources and action strategies to care for themselves in their environmental situation..$^{14,15}$

There were significant differences in mean SASE scores between the three age cohorts. This is in line with a similar study in rural areas in Norway, which points to the fact that advanced age leads to a decline both in self-care ability and self-care agency. ${ }^{43}$ Since self-care ability is required for selfcare activity, it is reasonable that self-care agency also decreases with advanced age. ${ }^{15}$ The differences in SASE scores seen in the current study indicate that people aged 85 years and above are less able to care for themselves than younger individuals.

It was surprising that $\mathrm{SOC}$ did not contribute to self-care ability, but this may be explained by the fact that SOC primarily influences perceived health, ${ }^{47}$ which was a positive factor for self-care ability in this study.

The majority of the participants in this study were in good mental health, which is an important issue concerning older people's abilities to manage their daily lives. Impaired mental health, measured by GHQ, was one of the strongest factors for lower self-care ability in the two oldest cohorts.

Satisfaction with life appeared to be another vital necessity for older people's self-care ability, ${ }^{15}$ and was especially important among the oldest people in this study. That respondents were satisfied with life may mean that age is of minor importance concerning older home-dwelling people's satisfaction with life in general. Other studies have shown that older people are as satisfied as young people., On the other hand, it seems that among home-dwelling people living alone, the oldest old (85+ years), with impaired health and decrease in social activities are those who have a difficult time. ${ }^{7}$ This could be the case in our study as well, taking into account the lower mean SASE score in the oldest cohort, as well as the larger number of individuals who received home nursing, perceived helplessness, and were anxious. It is likely also that the need for home nursing is a consequence of lower self-care ability, rather than home nursing being a cause of low self-care ability. ${ }^{15}$ 
Backman and Hentinen explored self-care among home care patients aged 75+ years, and reported that helplessness was not having the strength to care for oneself, and being dependent on others. ${ }^{49}$ The people in that study felt helpless for different reasons, such as being unable to read, not remembering things, or not having the ability to hear or to move, and these inabilities were linked to the wish to give up..$^{49}$ In addition, this group can be associated with the "fourth agers", recognized as a group characterized by frailty and independency, and understood as passive consumers of health care. ${ }^{6}$ It is important to underline the fact that in the current study there were significant differences between all three age cohorts in relation to helplessness, and that the oldest people were worst off. However, while helplessness was influential in the regression analysis in the two youngest age cohorts, it was not in the oldest cohort.

The present results indicate that urban people in southern Norway seem to cope with anxiety quite well. Other studies have investigated being anxious, and having fears or worries about the future. ${ }^{8,50}$ Anxiety may increase the risk of cognitive decline to a greater extent than the risk associated with increasing age,${ }^{51}$ which is an important fact regarding older people's mental health, particularly regarding the very old. This concern is due to the fact that observations and reporting of mental disease in older people is not recognized and less often assessed. ${ }^{52,53}$ However, being anxious was found to be negatively correlated to self-care ability only in the two youngest age cohorts in our study.

Moreover, recent studies by Momeni et $\mathrm{al}^{54}$ and Cuypers et $\mathrm{al}^{55}$ emphasize that social relations seem to be an important factor influencing mental health in old age. Therefore, it is important for health professionals to both observe and promote the mental health of those aged 65 to 74 years, so that they focus on social relations in their daily life.

Surprisingly, loneliness did not emerge as a factor associated with self-care ability. One explanation could be that the majority of the respondents were married or cohabitant. Another reason might be that those individuals who felt lonely were in the nonrespondent group.

The majority of the respondents in this study perceived themselves as being active, which might include activities beyond physical activities, ie, cultural activities, going to concerts, theatre, church, singing, dancing, doing parish work, gardening, or meeting friends and family. According to other studies about self-rated health and social capital, these types of social contacts are of most importance for the person's perceived health. ${ }^{55,56}$ One example of such activities in older people is music and singing. Skingley and Vella-Burrows' research, which was based on a systematic review on this topic, showed a wide range of self-reported benefits among older people living in the community including the finding that music added value to their life experiences, especially in helping to overcome the difficulties attributed to old age. ${ }^{57}$ The authors concluded that older people living at home should be referred by community nurses to community music or singing groups, especially for individuals who are socially isolated. ${ }^{57}$ Our results may indicate that older people living in urban areas in southern Norway live active lives and choose activities that suit them well, and this might have a positive impact on their health and self-care ability. ${ }^{15}$

The majority of the respondents were physically active every day, and it is well known that regular physical activity improves health. ${ }^{19,20,58}$ This result may explain the high score of self-care ability, good mental health, and life satisfaction in the current study as a whole, taking into account that the most vulnerable and sedentary people might be in the nonresponding group. Our results seem to indicate that being $85+$ years old reduces the frequency of physical activity and decreases the self-care ability among home-dwelling people, a result that is not surprising, ${ }^{9,15}$ but which gives an opportunity to present an important message to health professionals and politicians - it is critical to carefully study the consequences of an aging population in Norway as well as in other countries with a similar welfare system.

Frequency of physical activity is important for explaining the self-care ability in the oldest cohort. This finding should encourage interventions such as group exercise programs for senior citizens provided by trained instructors, and also unsupervised home exercise. According to Windle et $\mathrm{al},{ }^{59}$ primary care and voluntary services are well placed to promote these benefits. There is a decline in physical activity in later life, which may be related to a lack of opportunities or lack of encouragement. Frequency of physical activity was the strongest positive factors that explained self-care ability among the oldest people in the current study. Politicians and health care professionals in urban communities are important stakeholders both for making it possible for older people to get involved in physical activities and for encouraging them to understand the benefits of such activities, ${ }^{60}$ as well as being in a position to arrange and organize suitable infrastructures.

An older person's nutritional status influences his or her self-care ability. ${ }^{12}$ Because the oldest cohort in the current study was at greater risk of undernutrition, it should be an essential goal for nurses or other health professionals to use well documented instruments to assess people at risk of 
undernutrition, and also to promote nutritional health for old people living in their own homes.

Urban life seems to have a positive influence on older people's self-care ability. Although there were differences between smaller and larger towns, the practical differences may be difficult to discuss. Compared to a similar study from rural areas in southern Norway, ${ }^{43}$ factors were found that both positively and negatively influenced self-care ability. Being able to prepare food emerged as a positive factor for self-care ability in rural areas, and receiving help from family was found to negatively influence self-care ability. This was not the case in urban areas, where receiving home-nursing emerged as a negative factor for self-care ability. In both the present study and in the study by Dale et al, ${ }^{43}$ a negative relationship was found between receiving help and self-care ability. This may indicate that older urban people want help from the public health care system (rather than family help) to a greater extent than those in rural areas. Another explanation could be that older urban people are more often in need of professional help. The comparison also raises the question of whether older people in rural areas depend on their families rather than health care professionals. ${ }^{61}$ The study by Dale et $\mathrm{al}^{43}$ found a similar result to the current study in that higher self-care agency and being active both have a positive influence on self-care ability. Helplessness, greater age, and risk of undernutrition were negatively related to self-care ability in both studies. Age was particularly important as a negative factor for self-care ability in the cohort of individuals aged 75-84 years, which may indicate that a decline in self-care ability manifests itself clearly from the age of 75 years.

\section{Limitations of the study}

A sufficient sample for a large study of older home-dwelling people was obtained in this randomized descriptive, self-reported study in which one reminder was distributed, in accordance with the Regional Committee for Medical Research Ethics in southern Norway. Participants represented all of the five chosen counties in urban areas in southern Norway. The higher mean age and higher proportion of females among nonparticipants may indicate limitations that have to be taken into account. Individuals who did not participate may have been too sick or too weak to do so, or may have died. It is often difficult for older adults to participate in research, with age-related changes in functions (such as vision and hearing loss) affecting the person's ability to participate in a study that uses self-reported questionnaires. ${ }^{62}$ However, comparable patterns of nonrespondents have been seen in other similar studies. ${ }^{15,43}$
A less comprehensive questionnaire may have helped to produce a sample with a better gender balance and higher mean age among the participants. On the other hand, Jacelon argues that instruments may be too simplistic to capture the complexity of older people's views of the subject. ${ }^{62}$ However, we believe that our questionnaire with a number of tested instruments captured some of the complexity in older people's lives.

Due to the design of the current study, any generalization must be cautious, especially regarding females and the oldest old in particular.

\section{Conclusion}

This study indicates that urban older people in southern Norway are satisfied with their lives and have the ability to manage their self-care. They take care of their health and their households, manage their everyday lives so that they feel safe and secure, and they live active lives. Important health-promoting factors that enable this condition are good mental health, being satisfied with life, perceiving good health, being active, not being at risk of undernutrition, and being physically active once a week or more. So far, urban life seems not to be an obstacle for older people's self-care ability. Furthermore the results show that the oldest old of the people studied have worse mental health, are less physically active, and are more at risk of undernutrition. These results indicate that people aged $85+$ years are the most vulnerable group and require attention both from health professionals and politicians. Health professionals meet the oldest old in their homes and should focus on health-promoting factors that reinforce this group's self-care ability. Moreover, they should detect important symptoms, signs of poor mental health stage, and the risk of undernutrition, while encouraging physical activity.

In order to cope with the increased number of older people in the years to come, politicians have to prepare city municipalities so that older people who live in their own homes receive the best professional care, while also making it possible for them to receive accommodation if needed. Further studies concerning urban people and their physical activities and nutritional condition in self-care situations are needed, and the use of other research methods may be useful. This study indicates that health promotion among older urban people should focus on general health-promoting behavior and motivation, including physical, mental, and social activities.

\section{Acknowledgments}

We are grateful to all respondents. The project "Self-care and health among home-dwelling people in southern Norway" 
is carried out by the Centre for Caring Research - Southern Norway, Faculty of Health and Sport Sciences, University of Agder, and is financially supported by The Norwegian Research Council; project number 187985.

\section{Disclosure}

The authors report no conflicts of interest in relation to this paper.

\section{References}

1. World Health Organization. Global Age-friendly Cities: A Guide. 2007. Available from: http://whqlibdoc.who.int/ publications/2007/9789241547307_eng.pdf. Accessed February 28, 2011.

2. Byles J, Powers J, Chojenta C, Warner-Smith P. Older women in Australia: ageing in urban, rural and remote environments. Australas J Ageing. 2006;25(3):151-157.

3. Vlahov D, Freudenberg N, Proietti F, et al. Urban as a determinant of health. J Urban Health. 2007;84(3 Suppl):i16-i26.

4. Report No 25 (2005-2006) to the Storting. Long Term Care-Future Challenges: Care Plan 2015. Oslo, Norway: Ministry of Health and Care Services; 2006.

5. Statistics Norway. Befolkning og areal i tettsteder, tabell 2: folkemengde og areal i tettsteder. Kommune. 1. januar 2009. [Population statistics: Population and land area in urban settlements, 1 January 2009.] 2009. Available from: http://www.ssb.no/beftett/arkiv/tab-2009-2006-16-02. html. Accessed February 28, 2011.

6. Higgs P, Leontowitsch M, Stevenson F, Jones IR. Not just old and sick - the 'will to health' in later life. Ageing Soc. 2009;29(5):687-707.

7. Hansen T, Slagsvold B. Alder og livskvalitet: Eldre er tilfreds med livet - eller er det bare noe de tror? [Age and quality of life: Older people are satisfied with life - or is it just a figment of their imagination?] Samfunnsspeilet. 2009;23(1):95-99.

8. Kvaal K, McDougall FA, Brayne C, Matthews FE, Dewey ME, MRC CFAS. Co-occurrence of anxiety and depressive disorders in a community sample of older people: results from the MRC CFAS (Medical Research Council Cognitive Function and Ageing Study). Int J Geriatr Psychiatry. 2008;23(3):229-237.

9. Enkvist Å, Ekström H, Elmståhl S. Life satisfaction (LS) and symptoms among the oldest-old: Results from the longitudinal population study called Good Aging in Skåne (GÅS). Arch Gerontol Geriatr. 2012;54(1):146-150.

10. Eriksson M, Lindström B. Antonovsky's sense of coherence scale and its relation with quality of life: a systematic review. J Epidemiol Community Health. 2007;61(11):938-944.

11. Antonovsky A. Unraveling the Mystery of Health: How people manage stress and stay well. San Fransisco, CA: Jossey-Bass; 1987.

12. Söderhamn U, Bachrach-Lindström M, Ek AC. Self-care ability and sense of coherence in older nutritional at-risk patients. Eur J Clin Nutr. 2008;62(1):96-103.

13. Orem DE. Nursing: Concepts of Practice. St Louis, MO: Mosby-Year Book; 1991.

14. Høy B, Wagner L, Hall EOC. Self-care as a health resource of elders: an integrative review of the concept. Scand J Caring Sci. 2007;21(4):456-466.

15. Söderhamn O, Lindencrona C, Ek AC. Ability for self-care among home dwelling elderly people in a health district in Sweden. Int J Nurs Stud. 2000;37(4):361-368.

16. Murray C. Improving nutrition for older people. Nurs Older People. 2006;18(6):18-22.

17. Guigoz Y, Vellas B, Garry PJ. Assessing the nutritional status of the elderly: The Mini Nutritional Assessment as part of the geriatric evaluation. Nutr Rev. 1996;54(1 Pt 2):59-65.
18. Rennemark M, Lindwall M, Halling A, Berglund J. Relationships between physical activity and perceived qualities of life in old age. Results of the SNAC study. Aging Ment Health. 2009;13(1):1-8.

19. Lindwall M, Rennemark M, Berggren T. Movement in mind: the relationship of exercise with cognitive status for older adults in the Swedish National Study on Aging and Care (SNAC). Aging Ment Health. 2008;12(2):212-220.

20. Tse MM, Wan VT, Ho SS. Physical exercise: does it help in relieving pain and increasing mobility among older adults with chronic pain? J Clin Nurs. 2011;20(5-6):635-644.

21. Bassey EJ. Exercise for the elderly: an update. Age Ageing. 2002;31(S2):3-5.

22. Stålbrand IS, Svensson T, Elmståhl S, et al. Subjective health and illness, coping and life satisfaction in an 80-year-old Swedish population - implications for mortality. Int J Behav Med. 2007;14(3): 173-180.

23. Borglin G, Jakobsson U, Edberg AK, Hallberg IR. Older people in Sweden with various degrees of present quality of life: their health, social support, everyday activities and sense of coherence. Health Soc Care Community. 2006;14(2):136-146.

24. Werngren-Elgström M, Iwarsson S, Elmståhl S, Dehlin O. ADL dependence and perceived health among elderly deaf sign-language users: a comparison with a matched group of elderly hearing people. Scand J Occup Ther. 2005;12(2):81-88.

25. Lau R, Morse CA. Health and wellbeing of older people in Anglo-Australian and Italian-Australian communities: a rural-urban comparison. Aust J Rural Health. 2008;16(1):5-11.

26. Chang SH. Beliefs about self-care among nursing home staff and residents in Taiwan. Geriatr Nur. 2009;30(2):90-98.

27. Söderhamn O, Ek A-C, Pörn I. The Self-care Ability Scale for the Elderly. Scand J Occup Ther. 1996;3(2):69-78.

28. Pörn I. Health and adaptedness. Theor Med. 1993;14(4):295-303.

29. Söderhamn O. Health and the internal structure of the Self-care Ability Scale for the Elderly (SASE). Scand J Occup Ther. 2001;8(2): 67-71.

30. Söderhamn O, Lindencrona C, Ek AC. Validity of two self-care instruments for the elderly. Scand J Occup Ther. 1996;3:172-179.

31. Evers GCM. Appraisal of Self-Care Agency ASA-Scale. Assen, The Netherlands: Van Gorcum and Comp; 1989.

32. Söderhamn O, Evers G, Hamrin E. A Swedish version of the Appraisal of Self-care Agency (ASA) scale. Scand J Caring Sci. 1996;10(1): 3-9.

33. Lorensen M, Holter IM, Evers GCM, Isenberg MA, van Achterberg T. Cross-cultural testing of the "appraisal of self-care agency: ASA scale" in Norway. Int J Nurs Stud. 1993;30(1):15-23.

34. Söderhamn O, Holmgren L. Testing Antonovsky's sense of coherence (SOC) scale among Swedish physically active older people. Scand J Psychol. 2004;45(3):215-221.

35. Sullivan GC. Towards clarification of convergent concepts: sense of coherence, will to meaning, locus of control, learned helplessness and hardiness. J Adv Nurs. 1993;18(11):1772-1778.

36. Antonovsky A. The structure and properties of the sense of coherence scale. Soc Sci Med. 1993;36(6):725-733.

37. Söderhamn U, Söderhamn O. Developing and testing the Nutritional Form For the Elderly. Int J Nurs Pract. 2001;7(5):336-341.

38. Söderhamn U, Söderhamn O. Reliability and validity of the nutritional form for the elderly (NUFFE). J Adv Nurs. 2002;37(1):28-34.

39. Söderhamn U, Flateland S, Jessen L, Söderhamn O. Norwegian version of the Nutritional Form for the Elderly: sufficient psychometric properties for performing institutional screening of elderly patients. Nutr Res. 2009;29(11):761-767.

40. Goldberg DP, Hillier VF. Scaled version of the General Health Questionnaire. Psychol Med. 1979;9(1):139-145.

41. Caplan RP. Stress, anxiety, and depression in hospital consultants, general practitioners, and senior health service managers. $B M J$. 1994;309(6964):1261-1263. 
42. Dale B, Sævareid HI, Söderhamn O. Testing and using Goldberg's General Health Questionnaire: Mental health in relation to home nursing, home help, and family care among older, care-dependent individuals. Int J Ment Health Nurs. 2009;18(2):133-143.

43. Dale B, Söderhamn U, Söderhamn O. Self-care ability among homedwelling older people in rural areas in southern Norway. Scand J Caring Sci. 2012;26(1):113-122.

44. Altman DG. Practical Statistics for Medical Research. First edition. London, UK: Chapman and Hall/CRC; 1991.

45. World Medical Association. WMA Declaration of Helsinki: Ethical Principles for Medical Research Involving Human Subjects. Seoul, Korea: World Medical Association; 2008.

46. Beauchamp TL, Childress JF. Principles of Biomedical Ethics. Sixth edition. New York, NY: Oxford University Press; 2009.

47. Söderhamn O, Söderhamn U. Sense of coherence and health among home-dwelling older people. Br J Community Nurs. 2010;15(8):376-380.

48. Rush KL, Watts WE, Stanbury J. Older adults' perceptions of weakness and ageing. Int J Older People Nurs. 2011 June 30 [Epub ahead of print].

49. Backman K, Hentinen M. Model for the self-care of home-dwelling elderly. J Adv Nurs. 1999;30(3):564-572.

50. Gabriel Z, Bowling A. Quality of life from the perspectives of older people. Ageing Soc. 2004;24(5):675-691.

51. Wolitzky-Taylor KB, Castriotta N, Lenze EJ, Stanley MA, Craske MG. Anxiety disorders in older adults: a comprehensive review. Depress Anxiety. 2010;27(2):190-211.

52. Karlsson S, Edberg A-K, Hallberg IR. Professional's and older person's assessments of functional ability, health complaints and received care and service. A descriptive study. Int J Nurs Stud. 2010;47(10): 1217-1227.
53. Riedel-Heller SG, Busse A, Angermeyer MC. The state of mental health in old-age across the 'old' European Union - a systematic review. Acta Psychiatr Scand. 2006;113(5):388-401.

54. Momeni P, Wettergren L, Tessma M, Maddah S, Emami A. Factors of importance for self-reported mental health and depressive symptoms among ages 60-75 in urban Iran and Sweden. Scand J Caring Sci. 2011;25(4):696-705.

55. Cuypers K, Krokstad S, Lingaas Holmen T, Skjei Knudtsen M, Olov Bygren L, Holmen J. Patterns of receptive and creative cultural activities and their association with perceived health, anxiety, depression and satisfaction with life among adults: the HUNT study, Norway. J Epidemiol Community Health. 2011 May 23 [Epub ahead of print].

56. Nummela O, Sulander T, Karisto A, Uutela A. Self-rated health and social capital among aging people across the urban-rural dimension. Int J Behav Med. 2009;16(2):189-194.

57. Skingley A, Vella-Burrows T. Therapeutic effects of music and singing for older people. Nurs Stand. 2010;24(19):35-41.

58. Lim K, Taylor L. Factors associated with physical activity among older people - a population-based study. Prev Med. 2005;40(1):33-40.

59. Windle G, Hughes D, Linck P, Russell I, Woods B. Is exercise effective in promoting mental well-being in older age? A systematic review. Aging Ment Health. 2010;14(6):652-669.

60. Holmgren L, Söderhamn O. Perceived health and well-being in a group of physically active older Swedish people. Vård i Norden. Nursing Science and Research in the Nordic Countries. 2005;25(3):39-42.

61. Dale B, Sævareid HI, Kirkevold M, Söderhamn O. Older home-living patients perceptions of received home nursing and family care. Nordisk sygeplejeforskning/Nordic Nursing Research. 2011;1(3):220-234.

62. Jacelon CS. Older adults' participation in research. Nurse Res 2007;14(4):64-73
Journal of Multidisciplinary Healthcare

\section{Publish your work in this journal}

The Journal of Multidisciplinary Healthcare is an international, peerreviewed open-access journal that aims to represent and publish research in healthcare areas delivered by practitioners of different disciplines. This includes studies and reviews conducted by multidisciplinary teams as well as research which evaluates the results or conduct of such teams or

\section{Dovepress}

healthcare processes in general. The journal covers a wide range of areas and welcomes submission from practitioners at all levels, from all over the world. The manuscript management system is completely online and includes a very quick and fair peer-review system. Visit http://www.dovepress.com/testimonials.php to read real quotes from published authors. 